\title{
From the Editors: On Writing Up Qualitative Research in Management Learning and Education
}

In this editorial, I want to put a specific focus on how to write up qualitative work for submission to $A M L E$. My motivation comes from two observations. Since our team started our editorial role in July 2014, we have held a number of workshops around the world on publishing in AMLE. Many times, the discussions in the workshops I gave revolved around questions about qualitative work and, more specifically, around composing qualitative manuscripts for submission to AMLE. In addition, I noticed that authors of qualitative manuscripts submitted to the journol seem to be struggling with a number of specific issues related to writing and to making decisions about what should and should not go into the manuscript. As a result, we feel it is time to provide some guidelines for writing qualitative papers for $A M L E$ as well as some insights into what reviewers and readers alike are looking for in a qualitative manuscript on a management learning and education-(MLE) related topic.

From our experience, writing-related issues are among the most pervasive issues reviewers identify in qualitative papers (similar observations have been discussed in editorials in other journals, e.g., Gephart, 2004; Pratt, 2009; Ragins, 2012; Suddaby, 2006). In fact, many more substantive issues, such as the perceived lack of a theoretical contribution or issues with the execution of the research, are often rooted in shortcomings in the writing-up of the research. Frequently, reviewers bemoan that the authors simply did not provide enough information or not the right kind of information to assess whether a qualitative research project was conducted appropriately or whether the reported findings are well grounded in the data (Pratt, 2008).

A lack of relevance of the research paper for MLE scholarship is a second, very common reviewer concern that often contributes to rejection recommendations. MLE papers require on in-depth interaction

I would like to thank Michael Pratt, Catherine Welch, April Wright, Iris Fischlmayr, Chris Quinn-Trank, and Roy Suddaby for their invaluable comments on an earlier draft of this editorial. I would further like to thank Thomas Sasso and Maria Gloria GonzalezMorales for providing feedback after using the content of this editorial in their own work. with the MLE literature, in addition to an interaction with the applicable literature for the chosen research topic and with other discipline-specific literature (i.e., $\mathrm{OB}, \mathrm{HR}$, etc.). For example, when writing about strategic decision making in business schools, it is important that authors not only review literature on strategic decision making, but also integrate insights from the higher education literature on the business school context. Moreover, findings from the research first and foremost need to have implications for MLE research and then for the discipline or research-topic specific literature. This concern is primarily related to determining whether $A M L E$ is really the right torget journal for the authors' work.

My purpose here is to provide guidelines about writing up qualitative MLE research. We want to help authors compose papers that are written clearly, engage, tell an interesting story, pose challenging and meaningful questions, communicate transparent, appropriate, and rigorous methods, and present impactful, consequential, and thought-provoking findings. These papers are why we do our jobs as editors and reviewers. In addition, we believe that there are few things in an academic career that are as empowering, confidence generating, and selfefficacy building as having published a compelling paper and being recognized by others for the quality of one's work. At $A M L E$, we want to contribute to this process.

On the flip side, we do not want to make any prescriptions about how qualitative research needs to be conducted; rather, we want to provide authors with guidelines for what to report in their write-ups. At $A M L E$, we welcome research from a wide range of qualitative research traditions, epistemologies, and ontologies that promote different ways of conducting qualitative research. As Gibbert and Ruigrok (2010) found, although different qualitative research traditions such as positivism and interpretivism, might be in disagreement about what makes for high-quality and rigorous qualitative research, the research actions authors from both traditions chose to report in their papers to demonstrate rigor were astonishingly similar. As such, I want to focus in 
particular on the reporting of research actions that authors carried out. In doing so, I try to be as inclusive as possible to different qualitative research traditions but acknowledge that my chosen language might from time to time violates some epistemological and ontological traditions. I focus in my comments on the issues that I see most often and on the qualitative traditions most often applied in the submissions we receive at $A M L E$. I hope that authors and reviewers from various qualitative research backgrounds read the ideas communicated here in their intended spirit and not take offense as to the specific terminology I chose.

In developing our guidelines, I focused on four main themes-clarity, purpose, coherence, and transparency-which I briefly define here and then apply in the following sections of this editorial. Clarity refers to writing clearly, that is, providing relevant information in a way that eases the reader's understanding (see, e.g., Ragins, 2012). Clarity in a qualitative paper is greatly dependent on whether the paper follows a consistent and linear storyline (Golden-Biddle \& Locke, 2007; Ragins, 2012), in which each paragraph connects seamlessly to its preceding and subsequent paragraphs. There should be no jumps in argument or unnecessary exploration of side topics that do not aid significantly in the understanding of the topic at hand.

Purpose refers to stating clearly the motivation and aim of the manuscript, but also to purposedriven writing. Reviewers frequently bemoan that authors do not communicate the purpose of their research clearly enough. This includes not specifying clearly the actual research questions that the authors attempt to answer. Not communicating the purpose clearly means that a reviewer is not able to judge easily whether the conducted study actually serves that purpose. To communicate the research purpose and the study's attempt to fulfill this purpose to the reader, authors need to engage in purpose-driven writing. This means that everything the authors discuss in the paper (literature review, research question, methodology, report of findings, etc.) needs to be strongly linked to the purpose and to the actual research questions.

Authors establish coherence by ensuring that the description of the core phenomenon, the literature review exploring previous treatments of the phenomenon, the derived research question(s), the methodology chosen to investigate the phenomenon, the explanation of the findings that state how the data addresses the research question, and the discussion of implications of the findings for future work all align. Quite often reviewers notice that different parts of the paper do not align, when, for example, the research questions do not follow logically from the literature review, the research methods employed and findings obtained do not actually allow the authors to address their main research question (theory-data misalignment), or the Discussion section tries to derive implications that the findings do not really support. All of these are red flags to the reviewers (Pratt, 2008).

Transparency refers to providing enough relevant information about the unfolding of the research (i.e., the research actions), so that the reader can gain a thorough understanding of it. Reviewers commonly bemoan that an evaluation of the appropriateness of the research conduct, and thus, an evaluation of the trustworthiness of the findings, is impossible because how the research project unfolded remains unclear. Gibbert and Ruigrok (2010) provide excellent examples of the level of detail provided in more versus less rigorous qualitative case studies published in 10 top management journals. They highlight in particular that more rigorous studies are transparent about when and how the actual research process had to deviate from the planned one, while less rigorous studies reveal very little about the research process and more frequently portray it as if it had been carried out according to plan.

Derived from these four main themes, I provide in the following specific guidelines for writing a qualitative MLE manuscript, emulating the most common structure of a qualitative manuscript, that is, the sequence of literature review, methods, findings, and discussion. ${ }^{1}$ In each section, I provide concrete examples and refer the reader to relevant research methods literature and prior relevant editorials to

\footnotetext{
${ }^{1}$ Readers of this editorial will notice that I do not discuss how to write compelling Introduction or Conclusion sections. I decided against this for several reasons. First, the purpose and writing of introductions and conclusions are really not very different between different types of papers (i.e., quantitative versus qualitative, MLE versus non-MLE). Introductions need to provide the readers with a very good idea of the phenomenon the researchers are going to explore, the conundrum this phenomenon creates for existing theory or practice, and a short definition of the resulting open research questions that the study is going to address. Introductions also need to be written in a way that pulls in the reader. Conclusions, on the other hand, provide a final take-away message regarding the important findings and implications of the study and should be succinct. Second, a wealth of resources already exist that provide guidelines regarding the writing of great introductions and conclusions (see e.g., Golden-Biddle and Locke, 2007, Grant and Pollock, 2011, Huff, 1999, and Ragins, 2012.
} 
further support their writing. In addition, I provide authors with insights into some of the most common concerns that our $A M L E$ reviewers raise when reviewing qualitative work. Last, I introduce readers to a selection of qualitative papers published in $A M L E$ to showcase excellent writing. Table 1 contains a summary of pointers to keep in mind when writing a qualitative manuscript in MLE.

\section{LITERATURE REVIEW}

\section{Building a Case for Your Study and Its Contribution}

In the literature review, authors develop the motivation for the research question(s) they want to address and explain how an exploration of this research question adds something unique, novel, important, insightful, and impactful to ongoing debates in the existing literature. As such, they need to first establish the general topic they are interested in exploring and how this topic has been treated by prior research (e.g., Golden-Biddle \& Locke, 1993, 2007; Huff, 1999, 2009). For MLE papers, researchers need to ground their work in the MLE literature as well as in the literature of the substantive research field on which they plon to draw.

For example, if researchers wanted to examine how the strategic decision-making processes of business school deans influence expansion into education markets in other countries, they should incorporate into their literature review not only relevant literature in strategy, decision making, and international business regarding foreign market entry decisions, but also higher education literature that has looked into the expansion strategies and decisions of universities in general and business schools in particular. Similarly, if researchers wanted to explore the identity development process of international students as they join local fraternities and sororities, they should not only incorporate literature on identity and identity development in general, but also literature on identity development in students, in particular international students. They should also review literature on relevant characteristics of the international student experience that would be affected by joining fraternities and sororities.

We see many papers in the submission process that do not sufficiently anchor their research in both the MLE and the substantive literature of the phenomenon of interest. Linking the research to appropriate MLE literature (published in AMLE and in other MLE journals) is important to demonstrate the relevance of the research and its contribution to this field (e.g., Arbaugh, 2009). At the same time, authors need to review and integrate applicable research from other research fields (such as organizational behavior, strategy, international business, or human resource management, or research in other disciplines). If the reviewers believe the study would have turned out very differently had the researchers actually incorporated this literature, then they often recommend rejection given that the study does not adequately build upon and contribute to existing research. For more information, Ben Arbaugh $(2008$, 2009) has written two illuminating editorials that highlight what literature reviews need to entail, and Amy Kenworthy (2014) and Siri Terjesen and Diamanto Politis (2015) have written inspiring editorials on how MLE papers can benefit from incorporating different literatures.

Authors also need to be very clear from the start about what specific goal they pursue in their qualitative study and how the goal contributes to the extension of existing research. The purpose of a qualitative research project in the MLE field can be manifold, including the exploration and rich description of a novel phenomenon or teaching context (e.g., MOOCs, flipping classrooms, the effect of globalization on academic careers); understanding the meaning of lived experiences of individuals in academic contexts (e.g., students, academics, professional staff); exploring alternative explanations for phenomena (e.g., in a case study context); uncovering processes that underlie observable phenomena (such as learning processes); theory building (e.g., around pedagogy or learning); and many more. All of these purposes are welcome but require a slightly different approach to the literature review, the development of the core motivation of the paper, the resulting research question(s), and the definition of the main contributions to existing research. Clearly communicating the purpose of the study from the start helps readers evaluate the ensuing sections of the poper. The resulting research questions in particular need to be in line with the overarching gool of the paper, otherwise reviewers will feel a strong disconnect between what the paper claims it set out to do and what it actually accomplishes.

I want to acknowledge here that specific challenges exist for qualitative researchers in crafting a literature review. Although readers expect the authors to write a linear storyline, insightful qualitative research rarely unfolds in a linear fashion. Qualitative research often unfolds in on iterative, adaptive process, in which the research question, methods, and conclusions may change as the qualitative study is conducted. This often means that researchers learn crucial information about their 
TABLLE 1

Pointers for the Preparation of Qualitative Manuscripts for AMLE

\section{Manuscript section}

Literature review

Study setting and role of the researcher

Sample description and recruitment process

Qualitative method and research design

Interventions or tasks

\section{Guiding questions}

Does the paper clearly develop its motivation for the research question(s)?

Do the authors clearly communicate the purpose of the qualitative study?

Is the study clearly anchored in the MLE literature?

What is the study going to add to existing literature, especially the MLE literature?

Does the literature review integrate relevant literature specific to the chosen research topic and to the field in which it is situated?

Do the research questions follow logically from and are supported by the literature review?

Does the paper contain a transparent description of the methods used?

Is there alignment between the methods and research questions?

Does the paper contain a thorough description of the chosen research context and the process through which the researcher gained access to this context?

Does the researcher describe his or her role in this context and, if applicable, a reflection on possible issues with power?

Does the paper contain an explanation of how the chosen context allows the researcher to address the research question?

Is the chosen population in the context potentially vulnerable? Is the research topic in the context especially sensitive? Does the paper contain an explanation of how the researcher managed this?

Does the paper contain a description of the sample (including core demographics) and its appropriateness for exploring the research question?

Does the paper contain a description of the recruitment process and related potential limitations?

Does this paper contain a description of the chosen method and how it was employed, its appropriateness for addressing the research question, and its fit to the chosen research context?

Does the paper contain a description of research decisions and adaptations made during the research conduct and the underlying rationale for them?

Does the author provide an in-depth description of the intervention or task?

Does the author explain how their chosen intervention fits the research question?
Specific challenges and advice

Authors should write with clarity and employ a linear storyline. However, qualitative work rarely unfolds linearly, but rather in an iterative, adaptive process, in which the research question, methods, and conclusions may change as the qualitative study is conducted. Authors may need to go through multiple versions of a literature review to settle on a storyline that provides a clear message and strips away all the unnecessary details. Authors may need to acknowledge upfront that their literature review is informed by their findings and that they need to reveal some findings early to introduce the reader to core characteristics of the phenomenon.

Authors should communicate as strengths of the study characteristics of their chosen setting that allow them to address aspects of the research question in unique and meaningful ways. Authors should compare and contrast their setting to other common settings in which their research question likely matters. Authors should also acknowledge potential limitations that are inherent in the setting or in the method section rather than in the discussion section to allow the reader to be aware of these limitations before evaluating the appropriateness of the data collection and the value of the observations obtained in this setting.

Authors should communicate all relevant characteristics of the sample that might be critical for studying the research question.

Authors need to explain in detail how they realized and applied the chosen method and describe the taken research actions.

Authors should consider incorporating one or more forms of triangulation into their qualitative research design and describing triangulation efforts in the paper.

The description of the intervention needs to be detailed enough to enable the reader to design a similar type of intervention themselves.

(table continues) 
TABLE 1

Continued

\begin{tabular}{|c|c|c|}
\hline Manuscript section & Guiding questions & Specific challenges and advice \\
\hline Data-collection process & $\begin{array}{l}\text { Does the paper contain a detailed description of the } \\
\text { data collection process and its potential } \\
\text { limitations? } \\
\text { Does the author explain how the chosen data } \\
\text { collection process is appropriate to address the } \\
\text { research question? } \\
\text { Does the author provide an interview protocol/ } \\
\text { observation protocol/other data collection plan? }\end{array}$ & $\begin{array}{l}\text { In MLE research, many phenomena, processes, and } \\
\text { constructs of interest are very hard to observe or } \\
\text { capture (e.g., learning). Consequently, authors } \\
\text { should explain to the reader how their chosen data } \\
\text { collection methods allow them to access relevant } \\
\text { information concerning these phenomena, } \\
\text { processes, and concepts. }\end{array}$ \\
\hline Data-analysis process & $\begin{array}{l}\text { Does the paper contain a step-by-step description of } \\
\text { the coding process employed in the study? } \\
\text { Do the authors transparently describe their coding } \\
\text { decisions and the rationale behind them? } \\
\text { Does the paper contain an explanation of how the } \\
\text { researcher incorporated their own critical } \\
\text { reflections about the data collection and coding } \\
\text { process? }\end{array}$ & $\begin{array}{l}\text { Authors should not limit themselves to a "short- } \\
\text { hand" description instead of a full and detailed } \\
\text { description of their coding process. The less } \\
\text { information provided, the less trustworthy the } \\
\text { data analysis process may be perceived. }\end{array}$ \\
\hline Discussion & $\begin{array}{l}\text { Do the authors clearly communicate their study's } \\
\text { contribution to research, especially to MLE } \\
\text { research? } \\
\text { Do the authors clearly communicate their study's } \\
\text { contribution to teaching and learning practice or } \\
\text { to the operation of business schools? } \\
\text { Do the authors provide practical recommendations } \\
\text { that are well-grounded in the data and specific } \\
\text { enough to be implemented? } \\
\text { Does the paper include a discussion of limitations, } \\
\text { opportunities and strengths? }\end{array}$ & $\begin{array}{l}\text { Papers published in AMLE need to discuss their } \\
\text { contribution to MLE research and practice. } \\
\text { Specific practical implications for teaching and } \\
\text { learning or for the operation of business schools } \\
\text { are crucial and need to be a major part of the } \\
\text { discussion section. }\end{array}$ \\
\hline General & $\begin{array}{l}\text { Does the paper follow a clear, linear storyline? } \\
\text { Are all the sections aligned and coherent? } \\
\text { Does the purpose of the study remain clear } \\
\text { throughout the paper and is the overall writing } \\
\text { driven by that purpose? } \\
\text { Is the paper transparent throughout about its } \\
\text { research conduct? }\end{array}$ & \\
\hline
\end{tabular}

phenomenon as they research it, and as such, their literature review of the phenomenon changes. This creates two issues: First, in developing a clear storyline, authors often need to go through multiple versions of a literature review to settle on one that provides a clear message and strips away all the unnecessary details. Second, authors need to motivate the study of their phenomenon in their literature review by stating how they offer a new lens or how the phenomenon might need to be explored differently from previous examinations. However, often this already constitutes one of the core insights and conclusions from their study (especially in inductive studies). As such, authors run the risk of putting too 
much of their actual findings into the literature review, which con render the Findings section unsurprising given that the main contribution has already been revealed upfront. One way to resolve this issue is for authors to acknowledge upfront that their literature review is in fact informed by their findings and that they need to reveal part of their findings early to introduce the reader to core concepts and characteristics of the phenomenon.

Previous literature has done an excellent job in discussing how authors in general, and qualitative researchers in particular, should approach the literature review and the rationale for their study (e.g., Bansal \& Corley, 2012; Barley, 2006; Bartunek, Rynes, \& Ireland, 2006; Colquitt \& George, 2011; Golden-Biddle \& Locke, 2007; Huff, 1999; Pollock \& Bono, 2013; Pratt, 2009; Ragins, 2012). In addition, a wealth of resources discuss how studies can make theoretical contributions and how authors need to write about them (e.g., Bergh, 2003; Corley \& Gioia, 2011; Whetten, 1989). We refer readers to these and other resources, given that a more general discussion of writing good literature reviews goes beyond the scope of this editorial. Instead, we want to introduce the readers to a few examples of qualitative papers published in $A M L E$ that have done on exceptional job of developing the motivation for their research in their Literature Review section and of deriving their specific research questions.

Petriglieri, Wood, and Pertiglieri (2011), for example, examine an elective in on international MBA curriculum that provides students with on opportunity for deep reflection about their personal development and learning during their MBA program by working with a psychotherapist over the course of a year. In particular, the authors explore the processes through which this elective helps students engage in reflection on their learning and puts it into the context of their own life stories. The Literature Review section in this paper is particularly good because it marries a review of the literature on transformational learning with literature on identity workspaces, highlighting the need for a study that examines how the creation of identity workspaces can lead to transformational learning. Especially noteworthy is that the authors state very clearly what they mean to accomplish and which other research questions they are not going to examine:

The question then becomes not whether, but how can a management education curriculum foster the transformational learning that enables on-going leader development? This research question is our focus here. We are not concerned with assessing the prevalence of transformational learning in management education, testing the efficacy of one approach in fostering it, comparing different approaches, or proving causal links. We aim to develop theory that may inform scholarship and practice on this important question, through a qualitative study of participants' experiences within the Personal Development Elective and its MBA context (Petriglieri et al., 201 l: 433).

The paper is clearly aligned with the mission of $A M L E$ in that it addresses a key context of learning in business schools and builds theory with regard to the learning processes that particular teaching interventions create. Other great examples of successful literature reviews and motivations in $A M L E$ articles can be found in Elmes, Jiusto, Whiteman, Hersh, and Guthey (2012), Martin, Woods, and Dawkins (2015), and Reichard et al. (2014).

\section{METHODS}

\section{Establishing Rigor and Trustworthiness}

A Methods section needs to accomplish several core gools: The authors need to explain in sufficient detail exactly how they conducted their study (i.e., transparency of research actions); how their research approach aligned with the research question (i.e., purpose and coherence); and how their chosen methodology generated appropriate and relevant evidence visò-vis their research question (i.e., trustworthiness). In my experience, the main reasons for which $A M L E$ reviewers recommend rejection of a paper is a perceived misalignment between the chosen methodology and the specified research question or a lack of transparency in the Methods section to determine the appropriateness of the research actions taken. These observations align with Pratt's (2008) findings that between 56 and $75 \%$ of authors of qualitative studies submitted to top-tier North-American journals have received comments from editors or reviewers that bemoaned missing or inadequately described methods and analyses. On the flip side, Gibbert and Ruigrok (2010) found that the most rigorous qualitative case studies published in 10 of the top management journals were extremely transparent about their research actions, decision making, and necessary adaptations during the research process.

Qualitative papers in MLE, in particular, need to describe in detail the following aspects of their 
research methodology: The setting of their study (i.e., the research context); the sample (including sample characteristics and recruitment of the sample); the research design (which includes the type of qualitative method chosen and the specific application of this method in the current study); the teaching intervention or task given to the sample (depending on the topic of the paper); the data collection process (including information about the type and amount of collected data and the respective data sources from which different types of information were collected); and the data analysis process (i.e., the coding process). These sections do not necessarily have to be discussed in the particular order mentioned here; rather, authors should reflect on the order that best serves their storyline.

In many ways, these sections are very similar to the sections found in quantitative papers. However, in some ways they are also quite different and require more detailed information than we typically see in quantitative work. In my opinion, the level of transparency needed in these sections (that often goes beyond the transparency offered in quantitative work) is actually a strength of qualitative work and not an indicator that qualitative researchers are somehow less trusted. Rather, it is an acknowledgment of the fact that during the research process, a researcher has to make myriad decisions concerning the research design and its execution. Only when these decisions are made known to the reader, can the reader evaluate whether the chosen methodology was appropriate for the research question and skillfully carried out.

In a qualitative paper, a Methods section can quickly get out of hand. One only has to look at the length of my recommendations for the Methods section here to know that writing one requires lots of detail. However, it is important that a Methods section does not overpower the manuscript. Although it has to deliver everything needed for the reader to understand what the authors did and be convinced that the chosen approach was appropriate, this section is really only a means to an end. It stands between the literature review and the findings, that is, between the open research question and learning what the researchers have actually found. In that way, readers often want to simply be assured that the findings they are about to read are based on sound research methods and decision making such that they can move on to read the findings. Nevertheless, readers and reviewers appreciate rigorous methods, so highlighting all the core strengths of a research design is paramount. In the following, I offer some guidance about the kind of information authors should provide in each section and how this information could be delivered to maximize reader comprehension and perceived fit between the chosen approach and the research question. I also introduce published $A M L E$ papers again to showcase transparent and convincing methods sections.

\section{Study Setting and Role of the Researcher}

In qualitative work, the setting of a study-the research context, in which the research question was explored-is of utmost importance. At the center of much qualitative work is a phenomenon or specific construct that the researcher wants to understand and describe. This phenomenon or construct usually exists and operates in certain contexts but not in others. Understanding the relationship between the phenomenon and the context in which it exists is a major component of qualitative inquiry and can help the researcher identify important underlying mechanisms and dynamics relevant to the phenomenon. In addition, in choosing the research setting, $\alpha$ researcher needs to ensure that the phenomenon can actually be observed and studied and that researching the phenomenon in the chosen setting will likely provide rich and comprehensive information. Depending on the research question, indepth explorations of single contexts (e.g., single case studies) or explorations across multiple contexts can be appropriate.

For example, let's assume a researcher wanted to understand anxiety-related experiences in instructional settings of students for whom the main language of instruction is not their first. To examine this research question, it might be good to observe these students in a range of different instructional settings to learn more about how different instructional settings evoke different anxiety-related experiences and identify underlying factors and mechanisms that create different sources or levels of anxiety. Insights from this study could help understand how instructional settings might have to be redesigned to reduce the amount of anxiety that second-language students experience.

Accordingly, when writing about the chosen setting of a study, authors should explain to the reader how the setting provided an optimal context to address the research question. At the same time, in MLE research, in particular, some populations might be especially vulnerable, depending on many factors, such as the relationship of the participants with 
the researcher (e.g., teacher-student or head of department-department member). In addition, some research topics might be especially sensitive (e.g., stigmatization, prejudices, or bullying). Authors of such studies want to take extra care in their explanations of how they managed these contexts.

In a first step, the authors should thoroughly describe the research context they have chosen and the process or relationships through which they gained access to this setting (e.g., Dutton \& Dukerich, 2006). For papers on teaching interventions, for example, this might consist of a description of the class or subject in which the study was conducted, the type of university at which the class was held, and the country and academic system in which the university is situated. It would also need to contain a description of the role of the researcher in this specific class context, that is, whether the researcher is on instructor or an observer (e.g., another faculty member, student, teaching assistant, etc.). A description of the role should entail an explanation of the perspective the researcher had from this role and a reflection on the likely power relationships between the researcher and the participants. Both would influence what information and insights the researcher can possibly gain in the chosen setting (e.g., Pratt, 2009).

For papers exploring issues related to business schools, on the other hand, a description of the setting should include an in-depth description of the business school (including relevant information about its operational structure, faculty members, or whatever might be essential for the topic of the paper), the academic and country setting it resides in, and the particular situation it currently operates in (e.g., having just gone through a large strategic change, having been established for hundreds of years vs. being relatively young, etc.). For example, if the main research question of a paper revolves around how and in what way business schools change when going through an accreditation process, then the research context could include $a$ longitudinal case study of one or more business schools undergoing change or it could include a crosssectional case study of one or more business schools that are about to undergo an accreditation process, are currently undergoing such a process, or have undergone such a process recently. Each of these specific contexts would allow the researchers to observe slightly different things and would come with its own strengths and limitations.

Similar to the first example, researchers should also provide their position vis-ò-vis the research setting. For example, a researcher that is a faculty member or administrator in a business school that undergoes on accreditation process likely has a different perspective during the research process than a researcher who is unaffiliated with the chosen business school or a researcher who belongs to the accrediting institution. Providing this information allows a reader to determine how the specific instructional or organizational context and the role of the researcher might impact on the kind of observations that can or cannot be made.

Specific contexts can allow researchers to make observations and gain insights that they would not have been able to obtain in other contexts (e.g., Bamberger \& Pratt, 2010). It is thus very important that authors clearly communicate those characteristics of their chosen setting that allow them to address aspects of the research question in unique and meaningful ways. These are strengths of the study and should be highlighted as such to the reader. Moreover, authors should compare and contrast their setting to other common settings in which their research question likely matters. By describing the ways in which the chosen setting is similar to or different from these other possible settings, the authors can make a case for how data and findings derived from the current setting might be transferable to others. Readers can then determine the utility and applicability of the current study's insights for contexts in which they operate.

In addition to highlighting the unique strengths of the research setting, authors should also acknowledge potential limitations of the setting. In each setting there are boundories for the kind of information authors can obtain and the insights they can draw from the data. Limitations that are inherent in the setting or the design are preferably discussed in the Method section rather than in the Discussion section. This allows the reader to be aware of these limitations before evaluating the appropriateness of the data collection and the value of the observations obtained. For further information about the importance of the study setting and research context, we refer the reader to the following resources: Hatch, 2002; Locke, 2001; Lofland and Lofland, 1995; Malterud, 2001; Pratt, 2009; Ritchie and Lewis, 2003; and Yin, 2009.

\section{Sample Description and Recruitment Process}

Qualitative researchers also need to concern themselves with choosing an appropriate sample. On the one hand, it is important to ensure that the participants can in fact provide crucial information relevant 
for addressing the research question. On the other hand, it is also important that researchers think strategically about their sources of information such that they increase their chances to obtain a representation of the phenomenon in question that is sufficiently rich, multifaceted, nuonced, and diverse. In inductive qualitative research, this approach to sampling is termed purposive sampling and is one of its core characteristics. An important aspect of purposive sampling is that it is adaptive and iterative, meaning the actual sampling strategy might change during the study to adapt to the chosen context and obtain the most relevant information about the phenomenon. When the sampling strategy changes, authors should report this change and their rationale for it.

To start off, authors should provide a general description of the type of sample they selected, for example, undergraduate business students, MBA students, executives, business school deans, or leadership trainees. Authors should then explain how this sample allows them to address their research question (Bono \& McNamara, 2011; Zhang \& Shaw, 2012). For example, when the purpose of the study is to examine a specific teaching intervention, then business students are usually appropriate. If the purpose is to examine how a specific training intervention creates learning processes that lead to changes in executives' decision making, then a student sample that does not consist of executives is likely not appropriate.

A good example for the need to make a case for sample appropriateness is when authors submit papers to $A M L E$ that do not include a sample of business students, business school employees, or employees or managers in educational settings. AMLE's mission in particular is to address issues in management education and practices in business schools. As such, appropriate samples usually are situated in this specific context. Nevertheless, we do get papers that include samples outside of this context, for example, samples of students in other disciplines than business or employees in organizational training settings that have little to do with business or management education. This does not necessarily mean that studies conducted on such samples are inappropriate for $A M L E$ and will be rejected; however, the authors need to explain how findings generated from these samples will be relevant in and translate to the management education and business school context. More often than not, examples outside of the core management education area become a liability for the authors and a reason for a paper ultimately being deemed unsuitable for $A M L E$.

In addition to the need for this fundamental fit of the sample to the general context of MLE, excellent samples for studying the research question of interest allow researchers to gain valuable information and rich insights about the target phenomenon. Having clearly defined and described the target phenomenon and the core research question earlier in their papers, authors should now describe how the recruited participants can provide this information. Given that most interesting social phenomena are complex and multilayered, it is very likely that authors need to obtain information from different types of participants with access to different information.

Returning to our example of business schools undergoing change during an accreditation process, it is likely that change is different at different levels of the business school and for different types of employees. In addition, different types of employees at different levels likely have different involvement in, opinions about, and experiences during the accreditation process. All of these pieces of information, though, are important to address and understand the complexity of the outcomes of the accreditation process. Of course, it is not necessarily the case that every research question needs a $360-$ degree view of all potential stakeholders. This depends entirely on the research question; hence, the sample selection needs to align with the research question. The paper by Barbera, Bernhard, Nacht, and McCann (2015) published in AMLE provides an excellent example for showing the appropriateness of their sample and for involving different types of participants (i.e., students, parents, and course instructors) to obtain a more nuanced picture of how and why whole person learning aids in the education of the next generation of leaders of family businesses.

After describing the core characteristics of their sample and its appropriateness for the research question, authors should explain how participants were recruited into their sample. If, for example, all students in a course participated in a teaching intervention, the authors should explain whether students were able to opt in or out of participating in the intervention. If the researchers conducted a study of business school deans, they should explain how these deans were approached to participate in the study and what number of the deans ultimately agreed to participate. The final sample included in the study to some degree determines 
the information obtained. Authors might want to discuss the potential implications of their final sample for the exploration of the research question (e.g., Are important perspectives missing and why?). This will help the reader interpret the findings and conclusions drawn from them. An example of a very clear description of a sample recruitment process can be found in Martin et al. (2015).

Last, authors should provide core demographics about the recruited sample. It is surprising how often we see papers in which relevant demographic information is missing. Core demographic information usually includes age, gender, national or cultural background, and ethnicity. In student samples, demographics usually also contain year in their program, major, and prior work experience. In samples of members of organizations, demographics usually also include things such as position in the organization, tenure, work experience, and leadership responsibilities. This information can be important for the reader to determine whether the particular sample may be very different from the samples they typically encounter. In addition, it can provide information to the reviewer about the appropriateness of $\alpha$ particular sample.

However, authors should not just limit themselves to this type of information if there are other characteristics of the sample that might be critical for the research question. For example, if a researcher wanted to determine how students in an MBA program form social networks during a specific class or project, then the researcher needs to determine how many of the students knew each other before the course and how many of them, for example, belong to the same student associations, and thus, might already belong to certain social networks. Or, if a study proposes to determine what leaders learn from a particular leadership training program, we likely need to know about their prior leadership experience, their specific leadership responsibilities in the organization, and their position within the organizational hierarchy. All these aspects could be relevant for the reader's interpretation of the findings and should be communicated. For further information about comprehensive sample descriptions, we refer readers to Bamberger and Pratt (2010), Gephart (2004), Pratt (2009), Ritchie and Lewis (2003), and Suddaby (2006).

\section{Qualitative Method and Research Design}

After having described their research setting and sample, authors should describe the chosen qualitative method(s). It con often be helpful to first describe how the research question and chosen setting create certain requirements an appropriate method has to meet. The description of the chosen method can then specifically address how the method fulfills these requirements and allows the researchers to study the research question. In addition, the description of the method should discuss what information the method allows the researchers to uncover.

For rigorous reporting of the employed methods, authors need to go beyond a simple statement that they have used a particular method following a previous author's guidelines (see Gibbert \& Ruigrok, 2010), such as writing that they used the grounded theory method according to Glaser and Strauss (1967), Locke (2001), or Gioia, Corley, and Hamilton (2012) or a case study approach following guidelines by Eisenhardt (1989) or Yin (2009). Authors need to explain in detail how they realized and applied this approach in their study, that is, to describe their research actions (Gephart, 2004; Lee, 2001). More often than not, authors actually do not follow to the letter a particular approach suggested by previous research. Rather they make choices to adapt the suggested approach to optimally address their research context and question, which is considered one of the major strengths of qualitative methods. To demonstrate that these choices were reasonable and appropriate, authors should also provide the rationale behind their choices (Pratt, 2008). These reasons may include current best-practice recommendations from the research methods literature or pragmatic decisions related to the specific research context and situation. Whatever they may be, a high level of transparency is key in establishing rigor and trustworthiness (Gibbert \& Ruigrok, 2010; Pratt, 2009; Zhang \& Shaw, 2012).

For example, returning to the research question of how business schools might change when they undergo an accreditation process, one of the most predictable choices to explore this question would be a case study analysis that allows researchers to compare and contrast the experiences of different business schools (i.e., cases) that have undergone such a process or a longitudinal, single-case study of a business school undergoing on accreditation process from initiation to conclusion. The authors would first need to argue how a case study approach provided them with the information they needed to answer the research question, that is, how they used different business school cases to compare and contrast different events and experiences to analyze their effect on changes that these schools underwent. 
Alternatively, to explore the identity formation process of new international students who join local fraternities and sororities (our second example research question), researchers might choose a narrative study approach, following international students over the course of their first year to determine how students make sense of their new experiences and create $a$ new identity for themselves. In a first step, authors would need to explain how and why a narrative study would help them uncover students' identity formation process and how it would allow them to obtain information about relevant experiences that contributed to the students' sense-making process. This would entail an explanation of how the researchers plan to collect data over the course of the first year to map the identity formation process and the factors contributing to it (although authors could also write about this in the section on data collection).

To establish methodological rigor, I recommend to authors to consider incorporating one or more forms of triangulation into their qualitative research design. Depending on the chosen method and qualitative tradition in which a study is situated, triangulation may have different purposes and take on different forms. Triangulation essentially means that researchers look at a phenomenon from different angles to explore and understand it deeply. This can mean that researchers might combine different data or sources of information, utilize different methods to harness their respective strengths, integrate multiple theories to understand a phenomenon, employ different researchers to add different lenses and expertise, collect information at different times, and several other strategies (see Patton, 2002, and Yin, 2009, for excellent descriptions of different ways to triangulate). Some researchers may use triangulation to help corroborate findings, compensate for the shortcomings in particular methods, and to capture the richness and complexity of a phenomenon (Rouse \& Harrison, 2016). Others may use it to assess divergent findings across different triangulation strategies to better explore the underlying structures and dynamics creating the phenomenon and to obtain a better theoretical understanding of it (Bechky \& O'Mahony, 2016).

Reviewers are usually very appreciative of wellthought out triangulation designs, because they instill confidence that the researchers have explored a phenomenon in depth and that the conclusions are well derived. For a great example in an $A M L E$ paper, see Barbera, Bernhard, Nacht, \& McCann's (2015) use of data source triangulation by gathering information from students, parents, and course instructors; researcher triangulation by forming two researcher teams comprised of two researchers each (one internal and one external to the institution at which data were collected) to independently code the data and then discuss findings; and data analysis triangulation by comparing observations gained from different sources.

\section{Interventions or Tasks}

In MLE research, intervention studies or studies involving an instructional task are especially common (e.g., the application of a teaching method, a training program, a change in course structure, etc.). In their papers, authors need to provide on in-depth description of said intervention that entails a very specific description of the involved tasks, the timing of the intervention, required set-up, and other relevant information. If an author, for example, wanted to explore the value of student-consulting projects for developing work readiness, the reader would need to learn about the design and content of these projects, what learning goals were associated with them, how students were assigned to them, how students engaged with the clients during the project, how the course instructor interacted with the students, how conflicts were handled during the projects, how grades were determined (i.e., form of assessment), and many other pieces of information. Essentially, the description of the intervention needs to be detailed enough to enable the reader to design a similar type of intervention themselves. To remain within the confines of the required page limit for publications, it might be advisable to include a richer description of more elaborate teaching interventions in an appendix.

In addition, authors again need to make a strong case for how their chosen intervention allows them to address their research question. For example, if the main research question of a paper revolved around how and what students learn from tasks that are high in uncertainty and ambiguity, then the task chosen would need to be uncertain and ambiguous. It might then be contrasted with a nonambiguous one, depending on whether the authors wanted to draw conclusions about the differences in learning between tasks high and low in uncertainty and ambiguity. We want to point out two fantastic examples of clear, detailed, and transparent descriptions of interventions in AMLE papers: Elmes, Jiusto, Whiteman, Hersh, and Guthey's (2012) description of a project geared at teaching students 
social entrepreneurship, and Barbera, Bernhard et al.'s (2015) description of a leadership course for family business members focusing on whole person learning.

\section{Data-Collection Process}

A detailed description of the chosen data-collection process is crucial so that the readers and reviewers understand how the chosen approach aligns with the research question (i.e., theory-data alignment); what data are available; and also what limitations the chosen data-collection process might put on the findings. There are many potential approaches to collect data (such as interviews, observations, organizational documents, or pictures), and different research questions and settings might require a combination of these methods to be explored comprehensively.

Interviews are one of the most common sources of data in qualitative $A M L E$ submissions. Rarely, though, do authors actually explain why interviews were an appropriate methodology and how they conducted their interviews to obtain relevant information to answer their research question. When describing their interview approach, authors should identify the general approach (e.g., ethnographic or semistructured), and describe how this approach was executed in the study (i.e., research actions carried out). This includes information about how a typical interview unfolded and how long it usually took, where it was conducted, whether it was conducted by one or multiple interviewers, whether one or more interviewees participated at the same time, the approach to note taking during the interview, and what these notes were about. In addition, it is crucial to provide the actual interview protocol so that the reader can assess whether the questions asked allowed the researchers to elicit relevant information to address the research question without asking leading questions. A brilliant example of a clear, transparent, and detailed description of a data-collection process using interviews was written by Konopaski, Jack, and Hamilton (2015) in their study on how members of family businesses learn about continuity, such that their business remains thriving over multiple generations.

Similarly, if the authors collected information through observation, they need to make the case for how their observations afforded them unique insights into the phenomenon relevant to the research question. They then need to specify what types of observations they engaged in (e.g., participant observation, nonparticipant observation, covert, overt), and how these observations were carried out, including when the researchers chose to observe, where observations took place (i.e., in what context), what they chose to observe (e.g., interactions, behaviors, or incidents), and how these observations were recorded (e.g., field notes). In the spirit of triangulation, they might also describe whether different observations (e.g., observing different groups of students, different parts of a teaching intervention, or different types of meetings of a business school's executive board) allowed them to corroborate similar information through different means or obtain unique insights for theory building. If authors chose to employ multiple data-collection methods, it is helpful to explain how these were combined and used strategically to collect different perspectives on or characteristics of the phenomenon in question. Authors who have employed triangulation in this way should highlight this as a core strength of the study.

In MLE research, many phenomena, processes, and constructs of interest are very hard to observe. A prime example is learning itself. What constitutes learning can be manifold. The acquisition of factual knowledge is probably the easiest form of learning to observe; however, for qualitative researchers, it is also often one of the least interesting. Learning such as shifts in cognitive thought processes, identity development and struggles, development of competence and confidence, moral development, critical thinking, reflexivity, or self-awareness provide much more interesting study topics but are also much harder to observe. Consequently, authors should explain to the reader how their chosen datacollection methods allow them to access relevant information concerning these phenomena, processes, and concepts.

\section{Data-Analysis Process}

As Bansal and Corley (2011) found in their analysis of $A M J$ papers over the course of 10 years, most qualitative papers submitted to $A M J$ engage in some form of coding. Yet, as Gephart (2004), Suddaby (2006), and Pratt (2009) point out, a large number of submissions at $A M J$ do not adequately describe the coding process employed in the study. This is the same for papers submitted to $A M L E$. As such, my recommendations will predominantly focus on how authors should describe their coding process such that readers and reviewers gain a better understanding of how authors made sense of their raw 
data, uncovered underlying patterns in the data, and arrived at their observations and conclusions about the phenomenon in questions. This will help convince the reader that the conclusions drawn from the data are reasonable and justified.

In general, I recommend that authors provide a step-by-step description of their coding, starting with the processing of the raw data, its disassembly into meaningful thought frogments, its ordering into fragments of similar meaning, the interpretation of underlying categories of meaning, and so on. As in previous sections, there is a wealth of different data analysis approaches that all include their own best practices and guidelines, and numerous prior publications have provided excellent recommendations for describing the data-analysis process (e.g., Corbin \& Strauss, 2015; Krippendorf, 2004; Locke, 2002; Sonpar \& Golden-Biddle, 2008; Weber, 1990). I urge authors to ground their decision making in the available, relevant research methods literature. It is invaluable to provide appropriate information to the reviewers, as this will greatly smoothen the experience that authors will have in the review process.

Having just referred authors to previously published recommendations for coding, I want to mention one caveat that authors should be wary of: Authors are usually ill-advised when they provide a "shorthand" description instead of a full and detailed description of their coding process. This usually means that they refer to some form of template for conducting qualitative coding without explaining how they operationalized the coding in their study. Some authors might feel the need to cite a template approach so that their work looks more similar to a quantitative paper or so that reviewers will more likely perceive that the coding was carried out appropriately. However, the exact opposite is the case. The less information provided, the less trustworthy the data analysis process may be perceived to be (see also Gibbert \& Ruigrok, 2010).

When authors forego explaining in detail how they applied the respective approach in their study, reviewers tend to bemoan that they have no way of knowing exactly how the approach was applied and whether it was employed appropriately. Furthermore, reviewers and readers alike usually prefer to obtain a thorough understanding of how the researchers disassembled their raw data and reassembled it to arrive at lower level category definitions and higher level concepts and relationships between these concepts. They want to assess how the coding process employed might have affected the findings obtained with it.
Furthermore, coding decisions need to be made with the research question in mind, not by following a generic and rigid template. To demonstrate rigor in their data analysis, authors need to be transparent by providing rationale for their coding decisions and give examples of how they applied these decisions in specific instances of their coding process. Very often graphs and tables can be used successfully to help the reader understand how the coding process unfolded, and we highly recommend making use of these visual representations (see also Pratt 2008, 2009; Miles, Huberman, \& Saldaña, 2013). Moreover, graphs and tables can be employed to describe the coding process economically vis-à-vis the required page limit of the manuscript. For some great examples for the use of visual representations of the data analysis process in $A M L E$ papers, see Konopaski et al. (2015) and Barbera et al. (2015).

To establish confidence in the researchers' decision-making process and interpretation of the data, authors should further include an explanation of how they incorporated their own critical reflections about the data-collection process (i.e., field notes) and the coding process (i.e., memos) in their analysis to become aware of how their perspective and background might have influenced the conclusions they have drawn (e.g., Malterud, 2001; Van Maonen, 1979). If they have followed specific steps to counteract imbalanced interpretations (e.g., working in research pairs, recoding data from different angles with different theoretical lenses, (i.e., coding triangulation), then they should describe those as a strength of their process in the paper.

Generally, authors should take confidence in the fact that deviations from the standard approach are actually desirable when they allow the researchers to obtain insights that they would have not otherwise been able to obtain. As long as the coding decisions are well-argued and thought through, reviewers and readers are likely going to applaud the authors for employing an approach that fits their research question well. At the same time, we need to communicate to reviewers and readers of qualitative work that they need to refrain from making authors stick to templates; rather, they need to assess the authors' approach based on its own merit and appropriateness for their specific research context.

\section{Findings: The Fine Balance between Showing and Telling}

Findings sections are probably the hardest sections to write well. In part, this is because authors need to 
strike a very fine balance between presenting their data (i.e., showing) and interpreting that data (i.e., telling; Golden-Biddle \& Locke, 2007; Sandelowski, 1998). Just how fine that balance can be is apparent from Pratt's (2008) study of qualitative researchers who have submitted their papers to top-tier North American journals. He found that over $50 \%$ of the surveyed authors had received comments during the review process that they provide too much interpretation as compared with showing their data. At the same time, over $30 \%$ of the authors had received comments that they were showing too much data, while not providing enough interpretation.

We observe similar issues in qualitative papers submitted to $A M L E$. Many authors make the mistake of simply telling the reader what they found without involving the reader in the discovery process. This means that the reader is presented with statements about what the findings are, but not how the data actually support these findings, or how the researchers have arrived at their interpretations (i.e., too much telling, too little showing). On the flip side, authors can offer too much data with too little focus and interpretation (i.e., too much showing, too little telling). They provide a string of quotes (or quotes that are too long) to essentially provide a detailed summary of what their participants told them, without much interpretation of the meaning of these quotes. This can be an indication that the authors have not yet managed to sufficiently separate themselves from the raw data and abstract up to identify the underlying patterns and dynamics creating the phenomenon.

A compelling Findings section introduces the reader to core findings by providing relevant evidence from the data (e.g., through quotes) and an interpretation and analysis of what these findings mean. The primary purpose of $\alpha$ Findings section is to answer the research question. To do that, authors need to employ their data to build a chain of evidence that carries their findings. Consequently, authors need to think strategically about the presentation of their data such that it forms a coherent storyline that the reader can easily comprehend and follow, and that engages and convinces the reader (for an excellent treatment of writing up qualitative research, see Golden-Biddle \& Locke, 2007).

One step in this direction is to write a Findings section that focuses entirely on the discovery process of the reader. This means that authors need to be aware of the pieces of information readers need before they can understand the meaning and centrality of a core finding. As I mentioned above, often this means that basic findings might already be incorporated earlier in the paper (i.e., in the Literature Review). In this way, the researcher might create for the reader a foundation of knowledge of the phenomenon that is essential to understand what is ultimately unique or surprising about the phenomenon in the researcher's chosen context. The latter would then be presented in the Findings section by comparing and contrasting it to the foundation of knowledge provided earlier in the paper.

Another step in this direction is to be conscious of how information needs to be presented to the reader to be convincing and engaging. To be engaging, authors should first ensure that the context of the study comes to life for the reader. This means that the reader needs to feel that they have obtained a very good impression of the context, for example, such that they understand exactly the situation that an examined business school is in or such that they can hear the students' voices reflected in the findings. In some qualitative traditions, this is akin to providing a rich or thick description of the context. This can be achieved through providing essential quotes and observations from the data (i.e., showing).

To be convincing, the quotes and observations need to be interpreted (i.e., telling). The ideal goal here is that readers feel they actually got to know the data well enough to follow and understand the interpretations offered by the researchers. When a findings section is well written, a reader feels that they would have come to essentially the same conclusions as the authors. Furthermore, they feel intellectually engaged by the findings, meaning they form ideas about what this means for themselves, their own work, the larger theory landscape in an area, or for future research, before even arriving at the Discussion section. Findings sections like this get readers and reviewers excited.

There is no single best structure that Findings sections should follow to be engaging and convincing (see Sandelowski,1998, for on excellent piece on writing up one's findings). In my experience, a Findings section gets rewritten multiple times to converge on a version that seems to present the findings to the reader in the most accessible way. Also important is that authors present meaningful chunks of data and provide an interpretation of what the data mean (i.e., the analysis of the researcher). This interpretation has to go beyond a rewording of what an interviewee said or of what happened in an incident to establishing a link between what was observed and what we can learn from it to understand the phenomenon or answer the research question. 
In addition, authors need to ensure that they present "parts" of their story or their data in a way that the "whole" of their story or findings also makes sense. This means that authors need to keep in mind the big picture that they want the reader to understand, while they are providing evidence for the pieces that make up the big picture. Examples for great presentations of findings in $A M L E$ papers can be found in Barbera et al. (2015), Elmes et al. (2012), Konopaski et al. (2015), and Petriglieri et al. (2011). What all of these papers do particularly well, albeit in different ways, is that they communicate the findings clearly and convincingly to the reader by effectively using quotes, in-depth descriptions, and graphic visualizations to show their data. They also all have created successful structures to present their data in a way such that it becomes very easy for the reader to follow the authors' interpretations, while still being able to hear the voices of their participants.

On a more general note, I want to mention some good practices for providing quotes and observations in the Findings section (or in the associated tables). Authors should generally label each quote and observation with an anonymized code that captures the source of the information (i.e., a specific participant) and relevant information about the source. For example, when a study contains teachers and students, it might be helpful to distinguish between what teachers said and what students said. If the study contains students from multiple cultures, and culture is one of the core aspects of the research question, it would be useful to reflect in the label which culture a particular interviewee belonged to. Sometimes, it con even be helpful to reflect in the label the method with which the data were collected, for example: Teacher 1 - interview as opposed to Teacher 1 -syllabus. Authors need to determine what makes the most sense in their case.

Labeling quotes and observations has two main purposes. On the one hand, it helps readers keep track of who said what. It can allow authors to build interviewee profiles in their findings (if appropriate) or track the development of an individual over time (e.g., in a teaching intervention study) as just two examples. On the other hand, it also allows readers to determine whether the quotes used to support the authors' findings and interpretations have come from $\alpha$ rather small number of interviewees or are representative of many or all interviewees. It is not necessarily the case that all interviewees need to have reported the same issue for that issue to be deemed important and become a core finding.
Sometimes, only one individual might say something that allows the researcher to have a crucial insight about an ongoing dynamic in the research context. This can happen when one interviewee is particularly insightful or when that interviewee holds a core position in the context that allows him or her to know about information that other participants do not have.

At the same time, readers and reviewers usually want to know how prevalent a given observation was and how central it might have been to the participants' experience of the situation. Being able to show that some findings can be supported with quotes from several interviewees increases a reader's confidence in the representativeness of a reported finding (i.e., triangulation). At the same time, providing a quote that clearly demonstrates the connections between different concepts or aspects of the phenomenon can increase perceptions of relevance of the uncovered patterns in the data. In the end, it boils down to representing the data fairly, that is, reporting what is really there rather than what the researcher wants to be there. Previous work has provided excellent advice on how to use quotes and anecdotes strategically, and we refer authors to this work (Golden-Biddle \& Locke, 2007; Pratt, 2009, 2008; Yin, 2013).

\section{DISCUSSION}

\section{Why Does Your Study Matter and Where Do We Go From Here?}

Papers published in AMLE need to fulfill two purposes: making a contribution to MLE research (which includes theoretical contributions, but also, e.g., contributions to methodology) and making a contribution to MLE practice. Different from papers in other research specialty areas (e.g., organizational behavior, strategy, organizational theory, international business, etc.), practical implications for teaching and learning or for the operation of business schools are crucial and need to be a major part of the Discussion section. In addition, authors need to highlight the limitations, opportunities, and specific strengths of their papers, and end on a meaningful conclusion from their work.

\section{Contributions to Research}

Qualitative papers often establish a very strong link between their findings and discussion sections (Golden-Biddle \& Locke, 2007). After a brief summary of the core findings, qualitative papers can draw 
meaningful conclusions and implications from the findings for ongoing debates in the chosen research area. In defining a study's contribution to existing research on a topic, authors need to distill implications from the study's findings, that is, they should describe what the findings and interpretations mean for research and practice. Previous work has provided some excellent general recommendations for the identification and writing up of contributions, and we refer readers to these resources (see, e.g., Bergh, 2003; Corley \& Gioia, 201 l; Locke \& GoldenBiddle, 1997; Rynes, 2002; Whetten, 1989).

Here, I want to focus on advice for writing about contributions of MLE papers, which means that authors need to establish how their work contributes to ongoing research streams in the MLE domain. Although contributions to other domains (e.g., organizational behavior, strategy, etc.) are valuable and should be discussed, they should not be the main focus of the Discussion section. This is something that authors often struggle with when they submit their first paper to an MLE journal. Take as an example a paper that explored how a particular impression management training approach changes leaders' perceptions of their leader identity and selfefficacy. The focus of the Discussion section should not be first and foremost about how impression management, leader identity, and self-efficacy are related and how findings from the study contribute to our knowledge of these three constructs. Rather, the discussion section should discuss implications for impression management training approaches, the processes that led to learning and change in leader identity and self-efficacy, and how we can use this new knowledge about learning processes to change future research and practice in the area of leadership trainings.

One of the most common critique points in reviewer letters is that the discussion section of a particular paper does not in fact provide real implications for MLE research or that the contributions remain unclear. Another common critique point is that the contribution is not strong enough. This means that the implications that the authors derived from their findings and interpretations do not seem potent enough to change our thinking and theorizing about a specific teaching and learning approach or a particular practice in business schools. A third, commonly raised critique pointed out by reviewers is that authors sometimes extrapolate for beyond what their data and findings actually allow them to conclude. So, while underpinning the importance and relevance of their work, authors need to remain true to their data.
The question of how big a contribution needs to be to be considered a substantial contribution is one we often hear. It is hard to find an answer to this question, though. Judging from some of the most successful papers we have seen (some of them we gave as examples here), a contribution needs to make $\alpha$ solid change to the ongoing research debate on a topic, which could, among other things, be a change in variables we deem to be important, a meaningful change in our understanding of underlying processes, or a change in methodology or interventions. A convincing contribution often also makes us pause, reflect, and reevaluate how we think about a topic. In MLE research, this often goes hand in hand with the practical contributions derived from the findings. A great $A M L E$ example paper for this is Konopaski et al.'s (2015) paper, in which the authors show how several of their findings contradict and extend existing theory on participation and learning in family businesses. From these findings, the authors develop practical implications for consultants, members of family businesses, and educators in business schools.

\section{Contributions to Teaching and Learning Practice or to the Operation of Business Schools}

A core mission of the journal is to be practically relevant for instructors and teaching practitioners as well as for key stakeholders and decision makers in business schools. Consequently, readers and reviewers also place a strong emphasis on highquality practical implications. The recommendations made in this section need to be solid, well-grounded in the data, and meaningful. In addition, the recommendations need to be as specific as they can be. For example, if a paper explores how the incorporation of courses focusing on reflection fosters students' deep-level learning in an MBA curriculum, then good practical implications describe in as much depth as possible how these courses need to be designed, at which point they need to appear in the curriculum, and how they need to coincide with and complement other courses in the curriculum. It is not enough to simply state something akin to the fact that decision makers need to think about including reflective courses in their curriculum design.

To be practically relevant, the reader needs to learn about recommended best practices and about alternative approaches that lead to different outcomes. Especially in teaching-intervention papers, how and why an intervention worked needs to 
become clear. An excellent description of practical implications for developing educational resources can be found in Martin et al.'s (2015) paper on managing employees with mental health issues, in which the authors develop potential learning objectives for MBA curricula as well as provide a specific example of a case study that could be used in the classroom.

Of course, context factors are critically important for this, and authors are well advised to include the discussion of context factors in their Practical Implications section (Egri, 2013). Qualitative papers have a core advantage here over most quantitative papers because they are very solidly grounded in their particular research context. That means that authors can provide a rich description and analysis of how the context did or did not matter for their findings. In addition, due to the required detail in the Methods section, readers already receive a lot of information about the context, sample, and intervention (where applicable). So, in the Discussion section, authors can focus on a discussion of how transferable their findings and conclusions are and how they are likely going to matter for decision makers in business schools or for instructors of a range of different courses.

It is important to note here that qualitative papers are not concerned with generalizability. It is unlikely that findings from a qualitative study, which has been conducted in a very specific context on a very specific sample, can generalize widely. However, qualitative researchers do care about how their insights might be transferable to other contexts and samples. As such, a discussion on what makes the context and sample similar to or different from others is quite appropriate (see related suggestions in the Methods section).

\section{Limitations, Opportunities, and Strengths}

We recommend that similar to other papers authors include a section on limitations, opportunities, and strengths. In this section, the authors should briefly discuss how insights from their study are bound by the design and execution of the research. Authors do not need to discuss again their methodological choices or why they had to design their study in the way they did. They have already done that in the Methods section (see suggestions above). This section should, rather, focus on how characteristics of the sample, context, intervention design, and research context limit the conclusions that authors can derive. At the same time, authors should make constructive suggestions how future studies can examine specific issues that the current study did not address (i.e., opportunities). This is not the same as the contributions to existing research and the implications for future research discussed above on the section on research contributions. Rather, an identification of opportunities should focus on recommending further interesting contexts, somples, interventions, or methodological approaches that may provide new insights about the phenomenon in question. We also recommend that authors write a brief summary of the specific strengths of their study, its theoretical lens, research question, approach to address the research question, and methodology. Readers like to have a take-away message that encapsulates what is extraordinary and impressive about the study they just read. It is often important to end on this high note to maintain excitement about the study and to leave the reader engaged with the topic.

\section{Final Thoughts}

The purpose of this editorial is to help authors better understand what reviewers are looking for in qualitative papers and to provide some guidelines for navigating the manuscript writing process. Hopefully I leave readers more informed and more confident about their abilities to write up their qualitative research for AMLE. I further hope that I was able to inspire more researchers interested in MLE research topics to conduct and write up qualitative studies for submission to $A M L E$. We look forward to receiving all of the exciting manuscripts that are in the works out there.

\section{REFERENCES}

Arbaugh, J. B. 2008. From the editor: Starting the long march to legitimacy. Academy of Management Learning \& Education, 7(1): 5-8.

Arbaugh, J. B. 2009. From the editors: Raising the veil: Insights into AMLE's review process. Academy of Management Learning \& Education, 8(4): 479-482.

Bamberger, P. A., \& Pratt, M. G. 2010. From the editors: Moving forward by looking back: Reclaiming unconventional research contexts and samples in organizational scholarship. Academy of Management Journal, 53(4): 665-671.

Bansal, P., \& Corley, K. 2011. From the editors: The coming of age for qualitative research: Embracing the diversity of qualitative methods. Academy of Management Journal, 54(2): 233-237.

Bansal, P., \& Corley, K. 2012. Publishing in AMJ-Part 7: What 's different about qualitative research? Academy of Management Journal, 55(3): 509-513. 
Barbera, F., Bernhard, F., Nacht, J., \& McCann, G. 2015. The relevance of a whole-person learning approach to family business education: Concepts, evidence, and implications. Academy of Management Learning \& Education, 14(3): 322-346.

Barley, S. R. 2006. When I write my masterpiece: Thoughts on what makes a paper interesting. Academy of Management Journal, 49(1): 16-20.

Bartunek, J. M., Rynes, S. L., \& Ireland, R. 2006. What makes management research interesting, and why does it matter? Academy of Management Journal, 49(1): 9-15.

Bechky, B. A., \& O'Mahony, S. 2016. Leveraging comparative field data for theory generation. In K. D. Elsbach, \& R. M. Kramer (Eds.), Handbook of qualitative organizational research: Innovative pathways and methods: 168-176. New York, NY: Routledge.

Bergh, D. D. 2003. From the editors: Thinking strategically about contribution. Academy of Management Journal, 46(2): 135-136.

Bono, J. E., \& McNamara, G. 2011. From the editors: Publishing in AMJ_Part 2: Research design. The Academy of Management Journal, 54(4): 657-660.

Colquitt, J. A., \& George, G. 2011. From the editors: Publishing in AMJ-Part l: Topic choice. Academy of Management Journal, 54(3): 432-435.

Corbin, J., \& Strauss, A. 2015. Basics of qualitative research: Techniques and procedures for developing grounded theory, (4th ed.). Thousand Oaks, CA: Sage Publications, Inc.

Corley, K., \& Gioia, D. 2011 . Building theory about theory building: What constitutes a theoretical contribution? Academy of Management Review, 36(1): 12-32.

Dutton, J. E., \& Dukerich, J. M. 2006. The relational foundation of research: An underappreciated dimension of interesting research. Academy of Management Journal, 49(1): 2l-26.

Egri, C. P. 2013. From the editors: Context matters in management education scholarship. Academy of Management Learning and Education, 12(2): 155-157.

Eisenhardt, K. M. 1989. Building theories from case study research. Academy of Management Review, 14(4): 532-550.

Elmes, M. B., Jiusto, S., Whiteman, G., Hersh, R., \& Guthey, G. T. 2012. Teaching social entrepreneurship and innovation from the perspective of place and place making. Academy of Management Learning \& Education, 11(4): 533-554.

Gephart, R. P. 2004. Qualitative research and the Academy of Management Journal. Academy of Management Journal, 47(4): 454-462.

Gibbert, M., \& Ruigrok, W. 2010. The what and how of case study rigor: Three strategies based on published work. Organizational Research Methods, 13(4): 710-737.

Gioia, D. A., Corley, K. G., \& Hamilton, A. L. 2012. Seeking qualitative rigor in inductive research: Notes on the Gioia methodology. Organizational Research Methods, 16(1): 15-31.

Glaser, B., \& Strauss, A. 1967. The discovery of grounded theory. London, UK: Weidenfeld \& Nicholson.

Golden-Biddle, K., \& Locke, K. 1993. Appealing work: An investigation of how ethnographic texts convince. Organization Science, 4(4): 595-616.
Golden-Biddle, K., \& Locke, K. 2007. Composing qualitative research, (2nd ed.). Thousand Oaks, CA: Sage Publications.

Grant, A. M., \& Pollock, T. G. 2011. From the editors. Publishing in AMJ-Part 3: Setting the hook. Academy of Management Journal, 54(5): 873-879.

Hatch, J. A. 2002. Doing qualitative research in education settings. New York, New York: State University of New York Press.

Huff, A. S. 1999. Writing for scholarly publication. Thousand Oaks, CA: Sage Publications.

Huff, A. S. 2009. Designing research for publication. Thousand Oaks, CA: Sage Publications, Inc.

Kenworthy, A. L. 2014. From the editors: Lessons learned from dance-Cross-training as a tool for moving forward in our discipline. Academy of Management Leaning and Education, 13(2): 151-153.

Konopaski, M., Jack, S., \& Hamilton, E. 2015. How family business members learn about continuity. Academy of Management Learning \& Education, 14(3): 347-364.

Krippendorf, K. 2004. Content analysis: An introduction to its methodology. London, UK: Sage Publications.

Lee, T. 2001. On qualitative research in AMJ. Academy of Management Journal, 44(2): 215-216.

Locke, K. 2001. Grounded theory in management research. London, UK: Sage Publications.

Locke, K. 2002. The grounded theory approach to qualitative research. In F. Drasgow, \& N. Schmitt (Eds.), Measuring and analyzing behavior in organizations: 17-43. San Francisco, CA: Jossey-Bass.

Locke, K., \& Golden-Biddle, K. 1997. Constructing opportunities for contribution: Structuring intertextual coherence and "problematizing" in organizational studies. Academy of Management Journal, 40(5): 1023-1062.

Lofland, J., \& Lofland, L. H. 1995. Analyzing social settings, (3rd ed.). Belmont, CA: Wadsworth Publishing Company.

Malterud, K. 2001. Qualitative research: Standards, challenges, and guidelines. The Lancet, 358(panel 2): 483-488.

Martin, A., Woods, M., \& Dawkins, S. 2015. Managing employees with mental health issues: Identification of conceptual and procedural knowledge for development within management education curricula. Academy of Management Learning \& Education, 14(1): 50-68.

Miles, M. B., Huberman, A. M., \& Saldaña, J. 2013. Qualitative data analysis: An expanded sourcebook, (3rd ed.). Thousand Oaks, CA: Sage Publications, Inc.

Patton, M. Q. 2002. Qualitative research and evaluation methods, (3rd ed.). Thousand Oaks, CA: Sage Publications.

Petriglieri, G., Wood, J. D., \& Petriglieri, J. L. 2011 . Up close and personal: Building foundations for leaders' development through the personalization of management learning. Academy of Management Learning \& Education, 10(3): 430-450.

Pollock, T. G., \& Bono, J. E. 2013. Being Sheherazade: The importance of storytelling in academic writing. Academy of Management Journal, 56(3): 629-634. 
Pratt, M. 2009. From the editors: For the lack of a boilerplate: Tips on writing up (and reviewing) qualitative research. Academy of Management Journal, 52(5): 856-862.

Pratt, M. G. 2008. Fitting oval pegs into round holes. Tensions in evaluating and publishing qualitative research in top-tier North American journals. Organizational Research Methods, 11(3): 481-509.

Ragins, B. R. 2012. Editor's comments: Reflections on the craft of clear writing. Academy of Management Review, 37(4): 493-501.

Reichard, R., et al. 2014. Engagement in cultural trigger events in the development of cultural competence. Academy of Management Learning \& Education, 14(4): 461-481.

Ritchie, J., \& Lewis, J. 2003. Qualitative research practice: A guide for social science students and researchers. London, UK: Sage Publications.

Rouse, E. D., \& Harrison, S. H. 2016. Triangulate and expand: Using multiple sources of data for convergence and expansion to enrich inductive theorizing. In K. D. Elsbach, \& R. M. Kramer (Eds.), Handbook of qualitative organizational research: Innovative pathways and methods: 286-297. New York, NY: Routledge.

Rynes, S., 2002. From the editors. Academy of Management Journal, 45(2): 311-313.

Sandelowski, M. 1998. Writing a good read: Strategies for representing qualitative data. Research in Nursing \& Health, 21(4): 375-382.
Sonpar, K., \& Golden-Biddle, K. 2008. Using content analysis to elaborate adolescent theories of organization. Organizational Research Methods, 11(4): 795-814.

Suddaby, R. 2006. What grounded theory is not. Academy of Management Journal, 49(4): 633-642.

Terjesen, S., \& Politis, D. 2015. From the editors: In praise of multidisciplinary scholarship and the polymath. Academy of Management Learning \& Education, 14(2): 151-157.

Van Maanen, J. 1979. The fact of fiction in organizational ethnography. Administrative Science Quarterly, 24(4): 539-550.

Weber, R. P. 1990. Basic content analysis. London, UK: Sage Publications.

Whetten, D. A. 1989. What constitutes a theoretical contribution? Academy of Management Journal, 14(4): 490-495.

Yin, R. K. 2009. Case study research, (4th ed.). Thousand Oaks, CA: Sage Publications, Inc.

Yin, R. K. 2013. Case study research: Design and methods, (5th ed.). Thousand Oaks, CA: Sage Publications.

Zhang, Y., \& Shaw, J. D. 2012. From the editors. Publishing in AMJ-Part 5: Crafting the methods and results. Academy of Management Journal, 55(1): 8-12.

Tine Köhler The University of Melbourne, Australia 
Copyright of Academy of Management Learning \& Education is the property of Academy of Management and its content may not be copied or emailed to multiple sites or posted to a

listserv without the copyright holder's express written permission. However, users may print, download, or email articles for individual use. 